\title{
Revisão integrativa sobre cogestão no contexto da Política Nacional de Humanização
}

\author{
Co-management in the context of Brazil's National Humanization \\ Policy: an integrative review
}

Giovanna Cabral Doricci (https://orcid.org/0000-0003-2323-2368)1

Carla Guanaes-Lorenzi (https://orcid.org/0000-0001-6263-9078) ${ }^{1}$

${ }^{1}$ Faculdade de Psicologia, Universidade de Ribeirão Preto UNAERP. Av. Costábile Romano 2201, Ribeirânia. 14096-900 Ribeirão Preto SP Brasil. dorigica@gmail.com

\begin{abstract}
Co-management is one of the guiding principles of Brazil's National Humanization Policy (NHP), which has been studied since its creation in 2003. This article presents an integrative review of literature on co-management in the context of the NHP. We performed searches of the VHL, CAPES, Scopus and ProQuest databases for articles on co-management published after the creation of the NHP. We conducted a detailed analysis of 36 articles, organizing the results into two predefined categories: theoretical bases and reports on co-management in practice. The articles drew on the following theoretical bases: the circle method/institutional support, ergology, Hermeneutics, schizoanalysis, Habermas' theory of communicative action and Paulo Freire's pedagogy for liberation. Few studies provided original theoretical contributions. Regarding practice, the authors mentioned the implementation of co-management devices and the creation of different collective spaces, which were presented as a being participatory in themselves. The articles offered little reflection on the process of developing a culture of participation. We conclude by pointing to the need for studies that explore the relational construction of co-management in the everyday practice of health care teams.

Key words Health management, Humanization of care, Co-management
\end{abstract}

Resumo A Cogestão é uma das diretrizes da Política Nacional de Humanização (PNH), e vem sendo estudada desde a criação desta política. Apresentamos nesse artigo uma revisão integrativa da literatura nacional sobre Cogestão no contexto da $P N H$. Foram realizadas pesquisas nas bases de dados BVS, CAPES, Scopus e ProQuest em busca de artigos publicados após a data de implementação da politica e que abordassem a Cogestão. Realizamos a análise em profundidade de 36 artigos através de leitura, fichamento e organização dos resultados em duas categorias pré-definidas: aporte teórico e relatos sobre a prática. Sobre o aporte teórico, as publicações analisadas recorrem ao Método da Roda/Apoio Institucional, Ergologia, Hermenêutica, Esquizoanálise, Agir Comunicativo de Habermas e Pedagogia de Paulo Freire, sendo poucas as contribuições originais. Sobre a prática, os autores apresentam a implantação dos dispositivos da Cogestão e abertura de espaços coletivos, os quais têm sido abordados como participativos em si mesmos, havendo pouca reflexão sobre o processo de construção de uma cultura de participação. Assim, apontamos a importância de estudos que deem visibilidade de como se dá, na prática cotidiana das equipes de saúde, a construção relacional da cogestão.

Palavras-chave Gestão em saúde, Humanização da assistência, Cogestão administrativa 


\section{Introdução}

A proposta de gestão indicada como diretriz pela Política Nacional de Humanização (PNH), a Cogestão ou Gestão Participativa, fundamenta-se, em grande parte, na obra de Campos ${ }^{1}$, autor mais citado na cartilha de referência da PNH "Gestão Participativa e Cogestão" publicada pelo Ministério da Saúde $(\mathrm{MS})^{2}$.

Conforme apontam Pereira et al. ${ }^{3}$, em 2003, ano de implantação da PNH, Campos assumiu o cargo de secretário executivo da Secretaria Executiva do MS, quando uma série de seus conceitos passaram a compor as políticas nacionais desse Ministério. Por essa razão, e devido aos resultados obtidos na revisão, consideramos relevante apresentar nesta introdução norteadores básicos de sua obra e método, os quais têm sido amplamente difundidos e relacionados à Cogestão.

Contudo, vale destacar que a Gestão Participativa é um tema amplo, discutido no Brasil desde o Movimento da Reforma Sanitária ${ }^{4}$ o qual emerge na redemocratização, e posterior instituição de espaços para participação social, como os Conselhos ${ }^{5,6}$. Este tema tem sido também estudado desde a criação, em 2003, da Secretaria de Gestão Participativa no MS e elaboração da Política Nacional de Gestão Participativa ${ }^{4,7,8}$. Sem contar a produção em outros campos do conhecimento sobre cogestão na Sociologia 9 ; e modelos de gestão participativa na Administração e Psicologia Organizacional ${ }^{10}$.

Esses modelos participativos emergiram com maior intensidade a partir das décadas de $1960 \mathrm{e}$ 1970, e podem ser divididos em três categorias: modelos nos quais a participação é considerada como direito; modelos nos quais a participação significa maior comprometimento e melhor performance no trabalho, relacionado à humanização; e, participação como forma de controle das operações, um mecanismo de coordenação, como indicado por Mintzberg ${ }^{10}$.

Resgatar essa história quanto aos modelos de gestão existentes e sua inserção no campo da saúde ${ }^{11,12}$ escapa aos objetivos deste artigo, o qual buscou analisar o que tem sido produzido e relacionado à Cogestão após sua indicação como diretriz da $\mathrm{PNH}^{2}$. A seguir contextualizamos os norteadores centrais em Campos ${ }^{1}$.

O Método da Roda criado por Campos ${ }^{1}$ tem como objetivo analisar e cogerir coletivos, algo construído pela reformulação de conceitos da Administração, e saberes de outras áreas como Política, Psicologia, Filosofia e Pedagogia. São quatro eixos que o conformam: 1) O caráter
anti-Taylor; 2) Fortalecimento do Sujeito e Democracia institucional; 3) Reconstrução Conceitual e Prática do Trabalho; 4) A visão de mundo Dialética ${ }^{1}$.

No primeiro eixo, Campos ${ }^{1}$ posiciona sua criação como uma alternativa possível às demais teorias de Administração, em especial à Teoria Geral da Administração, de Taylor. Assim, para descrever o método o autor criou também uma fundamentação teórica, resultado do amalgama de outras teorias, a qual sustenta a prática proposta. O método busca instituir sistemas de Cogestão para produzir solidariedade ao interesse público e subjetividades autônomas e protagonistas. O segundo eixo discorre sobre os dois objetivos centrais do Método: o fortalecimento dos sujeitos e a construção da democracia institucional, sendo a criação de espaços coletivos a diretriz metodológica indicada. No terceiro eixo, Campos ${ }^{1}$ reconstrói o conceito "trabalho" a partir de uma influência das obras de Marx, o qual passa a ser considerado como um dos planos essenciais para a constituição de Sujeitos, de Coletivos e da Sociedade. Por fim, no quarto eixo discorre sobre a visão dialética de mundo na qual o Método se fundamenta.

Conforme indicado pelo autor, a criação de espaços coletivos têm três funções centrais: 1) administração e planejamento; 2) política, com alteração das relações de poder e construção da democracia; e por fim, 3) pedagógica e terapêutica, uma vez que influencia a produção de subjetividades, ao que ele chama de Fator Paideia. Como conclui Campos ${ }^{1}$ a ideia é:

Descentrar o foco da gestão, retirando-o da gestão de coisas, ou de tarefas, ou de procedimentos; centrando-o em administrar relações interpessoais e os resultados dessas relações. Para tanto haver-se -ia que repensar as funções de direção e os instrumentos até hoje empregados para desempenhá-las (p. 168).

Embora reconheça a possibilidade de diversas construções de espaços coletivos, a depender de cada contexto, Campos ${ }^{1}$ descreve quatro modalidades centrais: conselhos de cogestão; colegiados de gestão; dispositivos; e diálogo e tomada de decisão no cotidiano. $O$ autor apresenta ainda como possibilidade de aplicação do método o "Apoio Institucional" (fundamentado por referenciais do movimento institucionalista) com a participação de um agente externo, ou autoaplicação. $\mathrm{O}$ apoiador externo auxilia o grupo a promover análises de seus processos de trabalho e de suas relações, e é necessário perceber o movimento do próprio grupo e os afetos que circulam, a partir da transferência e contra-transferência ${ }^{1}$. 
Portanto, embora o autor ${ }^{1}$ não coloque dessa forma, e indique o apoio como prática, em nosso entendimento não podemos desconsiderar que, para efetuar determinadas análises, seja necessária habilidade e também que o apoiador possua conhecimentos oriundos das teorias de dinâmica e processo grupal, dos relacionamentos humanos, alguns conceitos da Psicanálise (uma vez que seu papel é perceber o movimento grupal e afetos que circulam a partir da transferência e contratransferência) e da própria Psicologia. Com isso queremos dizer que essa função de apoiador exige preparo, do contrário, corre-se o risco de se tornar um espaço vazio em termos de análise, como se a simples abertura da roda fosse suficiente para a construção de mudanças.

Com intenção de se tornar uma leitura acessível, o conteúdo da obra de Campos ${ }^{1}$ foi descrito de maneira simplificada na cartilha de referência com destaque para alguns aspectos e incluindo outros $^{2}$. Como descrito nela, o modelo de gestão adotado pela $\mathrm{PNH}$ está centrado no trabalho em equipe, A gestão não é um lugar ou um espaço, campo de ação exclusiva de especialista. Todos fazem gestão" (p. 23). O prefixo "co", do termo "Cogestão", indica duas inclusões: 1) da participação dos sujeitos nos processos de gestão; 2) ampliação das funções da gestão, que mais do que manter a organização funcionando, tem como objetivo analisar a instituição para problematizar modelos de operar/agir e promover mudanças; formular projetos; compartilhar tomada de decisões; e promover um espaço pedagógico de ensino e aprendizagem mútuos ${ }^{2}$. Portanto, a participação é vislumbrada para ocorrer no cotidiano dos serviços, e não apenas nos espaços previstos como Conselhos e Conferências de Saúde.

Ao considerar que a PNH é uma política aberta, que busca fomentar o protagonismo dos sujeitos em uma atuação contextualizada, não havendo normas ou regras, muitas experiências têm sido vividas pelos profissionais em seus cotidianos, boa parte das quais não tem sido publicadas como estudos empíricos, mas como relatos na Rede HumanizaSUS ${ }^{13}$. Nesse sentido, para além da cartilha, há um incentivo para que cada local construa, a seu modo, formas de compreender e de compartilhar a gestão. Assim, buscamos nessa revisão de literatura fazer um levantamento das publicações sobre essa temática, compreendendo que este não corresponde à totalidade de experiências empregadas no Brasil.

O objetivo geral dessa revisão é explorar a produção científica no Brasil sobre a Cogestão, após a criação da PNH em 2003. Os objetivos específicos são: a) identificar os aportes teóricos utilizados para discutir esse tema; b) identificar relatos sobre como a cogestão tem sido praticada.

De acordo com Botelho, Cunha e Macedo ${ }^{14}$, o processo de revisão da literatura é um primeiro passo para a construção de conhecimento, pois oferece aberturas para a execução de novas pesquisas através do reconhecimento das lacunas deixadas pelas produções analisadas. Assim, compreendemos que a revisão de literatura apresentada pode oferecer aos pesquisadores da área uma visão geral de parte significativa das produções e, ao mesmo tempo, convidar à publicação de experiências que não estejam contempladas nos textos analisados.

\section{Método}

Utilizamos como método a revisão integrativa, cujo objetivo é analisar o conhecimento construído sobre um determinado tema, o que pode gerar, além da síntese sistemática e ordenada do material analisado, abertura para novas pesqui$\operatorname{sas}^{14,15}$.

De acordo com Mendes et al. ${ }^{15} \mathrm{o}$ processo de elaboração da revisão integrativa inclui a consecução e descrição de etapas. Embora a literatura sobre esse tipo de revisão aponte a necessidade de sistematização e de descrição dessas etapas, há diferentes formas de subdivisão, a depender do autor.

A revisão apresentada contempla as etapas definidas por Mendes et al. ${ }^{15}$, e foram descritas nesse artigo da seguinte forma: construção de questão norteadora; critérios para seleção e exclusão das produções; ensaios - a fim de obter os descritores / palavras-chave -, escolha das plataformas e descritores; análise de resumos e títulos; seleção preliminar; leitura em profundidade e fichamento; refinamento da seleção; análise, interpretação e apresentação dos resultados.

\section{Questão norteadora}

Considerando a abertura que a PNH oferece para que suas diretrizes sejam colocadas em prática respeitando os contextos locais, definimos como questão: como a gestão, ou mais especificamente, a diretriz Cogestão, tem sido discutida e relatada na prática desde a criação da política em 2003? Há nessa questão duas categorias para análise posterior: a) aporte teórico; b) relato da cogestão na prática. 


\section{Critérios de seleção preliminar}

O critério de seleção no momento de análise dos títulos e resumos foi abordar, como assunto central, o modelo de Cogestão no contexto específico de saúde pública brasileiro, ou a gestão e processos de trabalho em saúde conforme fundamentados pela cartilha base da $\mathrm{PNH}^{2}$.

\section{Critérios de exclusão}

Após seleção preliminar e análise em profundidade das produções, foram excluídas as que, embora citassem o tema, não o abordavam como objeto de estudo ou discussão central.

\section{Ensaios, escolha das plataformas e seleção preliminar}

Os ensaios e as buscas foram realizados em 2016. A primeira busca foi realizada no portal de pesquisa da Biblioteca Virtual em Saúde (BVS), escolhida por ser uma das mais utilizadas na área da saúde no Brasil. O resultado mais expressivo, após os ensaios com diferentes descritores e/ou palavras-chave, foi o cruzamento das palavraschave "Gestão AND Humanização", resultando em 429 textos. Após inclusão de filtro em relação ao ano de publicação - de 2003 (ano de criação da $\mathrm{PNH}$ ) a 2016 -, restaram 404 textos.

Selecionamos 45 textos, dentre artigos, livros e teses para leitura em profundidade, o que corresponde a $11 \%$ do total. Não contabilizamos como selecionados 24 repetições desses 45 textos, as quais, não obstante, fazem parte dos 404 textos resultados da pesquisa. Os demais 335 foram categorizados e contabilizados: $49 \%$ abordavam a política, porém com enfoque em outros dispositivos/diretrizes; $4 \%$ abordavam a formação profissional; $2 \%$ Psicologia ou da Odontologia no contexto de saúde; $28 \%$ assuntos em saúde que esbarravam na humanização como: doação de órgão, tratamentos etc.

A segunda pesquisa foi realizada no Portal CAPES que agrega bases multidisciplinares. Após experimentações, as palavras-chave escolhidas foram: "health management AND humanization", resultando em 53 textos. Desses, 15 abordavam o assunto central e foram selecionados, mas dentre eles, seis já haviam sido selecionados na BVS e sete se repetiam, tendo restado apenas dois artigos novos. Os demais foram categorizados: $17 \%$ abordavam a humanização com foco diferente; $13 \%$ assuntos que se esbarram na humanização; 4\% tratavam de biotecnologia; e 38\% assuntos diversos, como, por exemplo, o recobrimento cerâmico em compósito de carbono etc.

A terceira pesquisa foi realizada no portal Scopus que agrega bases multidisciplinares em diferentes áreas. Após ensaios, as palavras-chave mais adequadas foram "health management AND humanization", obtivemos 155 resultados. Desses, 21 textos foram selecionados, dos quais 16 já haviam sido selecionados na BVS, e um já havia sido identificado no portal CAPES. Apenas quatro, dentre os 21, eram novos, considerando as pesquisas anteriores. Os demais foram contabilizados e categorizados: $60 \%$ humanização com outro foco; $14 \%$ discussões no campo da saúde que se esbarram na humanização; $2 \%$ gestão em outros contextos; $10 \%$ assuntos diversos.

A quarta pesquisa foi realizada no portal ProQuest que agrega bases de dados em diferentes áreas. A principal busca, após tentativas, foi feita utilizando-se a seguinte combinação de palavraschave e descritores: "Health management AND humanization of work OR humanization". Foram identificados 35 resultados. Desses, quatro foram selecionados, mas um deles já havia sido encontrado na BVS, Scopus e CAPES, e um na BVS e Scopus, portanto apenas dois eram novos. Os demais foram categorizados e contabilizados: 26\% humanização com outro foco; $46 \%$ gestão do trabalho, mas não na saúde; $3 \%$ humanização em outras áreas; e 14\% saúde em geral.

Ao final das quatro pesquisas, concluímos a seleção preliminar dos títulos e resumos, para então buscar o material completo e realizar a leitura e análise em profundidade. $\mathrm{O}$ resultado dessa seleção preliminar compõe 53 produções, 45 delas do portal BVS, quatro do portal Scopus, dois do portal ProQuest, e dois do Portal CAPES.

Após busca do material completo e leitura em profundidade dos textos e fichamento, 17 foram excluídos. Dentre esses, estavam artigos não encontrados em sua íntegra, teses ou dissertações referentes a artigos publicados, e artigos em que a discussão não estava centralizada na gestão considerando a PNH. Portanto, as reflexões apresentadas referem-se à análise de 36 textos. O Quadro 1 traz os textos analisados, organizados por ano de publicação.

\section{Procedimentos de análise}

A partir de leitura e fichamento, com preenchimento de ficha elaborada no Programa Microsoft Excel (itens: título, autores, formação autores, ano publicação, revista, resumo, método, conclusões), analisamos o material destacando as 
Quadro 1. Textos analisados.

\begin{tabular}{|c|c|}
\hline \multicolumn{2}{|r|}{ Referência } \\
\hline 2006 & 52. Brasil (2006) \\
\hline 2008 & 45. Hennington (2008) \\
\hline \multirow[t]{9}{*}{2009} & 17. Mori e Oliveira (2009) \\
\hline & 39. Mori, Silva e Beck (2009) \\
\hline & 37. Santos Filho e Figueiredo (2009) \\
\hline & 40. Trad e Espiridião (2009) \\
\hline & 30. Santos Filho et al. (2009) \\
\hline & 31. Guedes, Pitombo e Barros (2009) \\
\hline & 44. Heckert, Passos e Barros (2009) \\
\hline & 34. Pasche (2009) \\
\hline & 42. Ceccim e Merhy (2009) \\
\hline \multirow[t]{4}{*}{2011} & 41. Pasche, Passos e Hennington (2011) \\
\hline & 51. Cardoso e Hennington (2011) \\
\hline & 32. Barros, Guedes e Roza (2011) \\
\hline & 47. Santos e Santo (2011) \\
\hline \multirow[t]{5}{*}{2012} & 49. Araújo e Pontes (2012) \\
\hline & 29. Guedes, Roza e Barros (2012) \\
\hline & 36. Granja e Zoboli (2012) \\
\hline & 2. Brasil (2012) \\
\hline & 53. Brasil (2012) \\
\hline \multirow[t]{2}{*}{2013} & 50. Becchi et al. (2013) \\
\hline & 35. Rios e Batistella (2013) \\
\hline \multirow[t]{11}{*}{2014} & 19. Mori e Oliveira (2014) \\
\hline & 24. Calderon e Verdi (2014) \\
\hline & 22. Maerschner et al. (2014) \\
\hline & 23. Pinheiro e Jesus (2014) \\
\hline & 21. Martins e Luzio (2014) \\
\hline & 25. Santos Filho (2014) \\
\hline & 26. Pavan e Trajano (2014) \\
\hline & 20. Shimizu e Martins (2014) \\
\hline & 27. Roza et al. (2014) \\
\hline & 28. Andrade et al. (2014) \\
\hline & 48. Ferreira e Araújo (2014) \\
\hline \multirow[t]{2}{*}{2015} & 38. Deus e Melo (2015) \\
\hline & 18. Pereira e Ferreira Neto (2015) \\
\hline 2016 & 33. Cardoso, Oliveira e Furlan (2016) \\
\hline
\end{tabular}

Fonte: Elaborado pelas autoras.

duas categorias pré-estabelecidas (aporte teórico e relatos da prática).

Após fichamento, retomamos a leitura com o objetivo de reduzir as informações em uma planilha única no Excel, que contemplava: 1) título do artigo; 2) formação autores; 3 ) ano publicação; 4) revista; 5) aporte teórico; 6) relatos da prática; e 7) base de dados. Com as informações descritas objetivamente, foi possível fazer um levantamento através da utilização de filtro, que corresponde a um recurso para contagem das informações no programa Excel.
O referencial utilizado para a discussão dessa análise, principalmente no que se refere às perspectivas do aporte teórico e relatos da prática, incluiu a obra de Campos ${ }^{1}$ e, também, a cartilha específica sobre Cogestão ${ }^{2}$ já apresentados e justificados na introdução.

Para que a análise das categorias fosse possível, foi necessário efetuar recortes nos artigos (muitas vezes dando destaques para aspectos secundários dos textos), o que significa dizer que a revisão aqui apresentada é uma construção de sentido $^{16}$ com objetivo específico de explorar o campo. Essa construção coloca em evidência, portanto, aspectos que não necessariamente eram colocados em evidência intencionalmente pelos autores dos textos.

\section{Resultados}

Dentre as trinta e seis produções localizadas, $5,5 \%$ foram publicadas entre 2006 e $2008,25 \%$ em 2009, $11 \%$ em 2011, 14\% em 2012, 6\% em 2013, $30 \%$ em 2014 e $8,3 \%$ entre 2015 e 2016 . Constatamos boom de publicações nos anos 2009 e 2014. Uma hipótese para esse resultado corresponde ao aniversário da PNH, que em 2009 completou cinco anos de existência, e em 2014, completou dez anos. Geralmente, as revistas promovem números especiais temáticos em datas comemorativas.

Essa hipótese pode ser melhor sustentada quando realizamos um levantamento das revistas em que esses artigos foram publicados. Os resultados mais expressivos correspondem à Revista Interface, com 18 produções, e à Revista Ciência \& Saúde Coletiva com quatro artigos. Em 2014 a Interface promoveu uma edição especial suplementar com o nome "Apoio Institucional na Política de Humanização". Dos 18 artigos encontrados nessa Revista, dez foram publicados nessa edição especial. Com dois artigos publicados estavam as revistas Saúde e Sociedade e Trabalho, Educação e Saúde, e as demais revistas com apenas um artigo (Cadernos de Saúde Pública, O mundo da Saúde, Physis: Revista de Saúde Coletiva, Revista Pan -Amazônica de Saúde, Revista Saúde Pública, Saúde em Debate, Textos \& Contextos), além das três produções em cartilha do Ministério da Saúde.

Chama também atenção em relação a essa análise geral, a formação dos autores que discutem a temática. A maioria dos autores, o que corresponde a 38\% do total, são formados em Psicologia, seguidos por 23\% de autores formados em Enfermagem e $17 \%$ em Medicina. Em menor quantidade estão autores formados em Odontologia $(4,7 \%)$, 
Serviço Social (4,7\%), Ciências Sociais (1,57\%), Educação Física (3\%), Terapia Ocupacional (3\%), ou não foi localizada a formação $(3,10 \%)$. Como hipótese para esses resultados apontamos a ideia de que a PNH, conforme cartilha de fundamentação, se esbarra nas produções da Psicologia, pois dialoga com questões subjetivas, como as relações interpessoais, e no caso da gestão, com conhecimentos oriundos da Psicologia Organizacional, Educacional e Institucional.

\section{Aporte teórico}

A análise do aporte teórico utilizado nos artigos demonstrou-se uma tarefa complexa. Alguns artigos partem de um referencial epistemológico específico e dialogam com autores que o compartilham, ou com autores que possuem referencial distinto do escolhido, mas sempre indicando as diferenças epistemológicas centrais. Outros, porém, dialogam com diferentes perspectivas epistemológicas e diversos autores. Sobre estes, em alguns casos, uma tarefa árdua identificar se há uma afiliação a algum aporte teórico específico, ou se citam diversos por escolha ou desconhecimento do campo.

De maneira geral, as discussões dos artigos sustentavam suas introduções e/ou análises nos seguintes aportes teóricos: fundamentação teórica criada, com base em outras teorias clássicas, que deu origem ao Método da Roda / Apoio Institucional'; Esquizoanálise (Deleuze e Guattari); Ergologia (Schwartz); Hermenêutica (a partir de autores como Gadamer e Heidegger); noções do campo da Sociologia - Habermas; e a Pedagogia de Paulo Freire. Boa parte dessas perspectivas são utilizadas por Campos ${ }^{1}$ em sua obra para desenvolver o Método da Roda, a única não trabalhada pelo autor corresponde à Ergologia.

Com isso é possível notar, como resultado central dessa revisão, a difusão da produção de Campos como referência-base da cogestão em $\mathrm{PNH}$, possivelmente devido à cartilha divulgada pelo Ministério da Saúde. Contudo, isso não quer dizer que o autor seja a origem de modelos de gestão participativa, conforme indicado na introdução, mas nota-se que sua influência nas produções localizadas pode, aos poucos, produzir essa ideia como parte da produção de conhecimento relacionada à temática. Este aspecto pode ser considerado uma lacuna importante a ser analisada por pesquisas que tenham como objetivo resgatar as origens da gestão participativa e surgimento da cogestão nesse contexto.

Alguns dos artigos dialogam de modo específico com a proposta do Apoio Institucional apre- sentada pelo autor ${ }^{17-33}$. Dentre esses artigos, Santos Filho ${ }^{25} \mathrm{faz}$ uma análise do Apoio Institucional utilizando como referência os autores Schwartz e Zarifian, da Ergologia, que incluem discussões pertinentes sobre a importância de se trabalhar as relações e a comunicação para promoção de mudanças.

Outros artigos utilizam as diretrizes da $\mathrm{PNH}$ e/ou a discussão apresentada no livro de Campos ${ }^{1}$ como norte teórico para realizar suas discussões, sendo algumas mais específicas sobre gestão e outras com outro foco, mas com atenção dada a este tema ${ }^{34-40}$. Esses artigos, em termos teóricos, não nos pareceram acrescentar novas ideias ao campo de conhecimento utilizando as teorias ou conceitos já presentes em Campos ${ }^{1}$. Contudo, é possível que as relações conceituais possam ser consideradas inovadoras a depender da perspectiva de análise. De maneira geral, alguns descrevem experiências pautadas no referencial tradicional ou pesquisas de campo a partir desse referencial $^{35-38,40}$, e apenas um apresenta uma inovação metodológica ${ }^{39}$.

Outro aporte teórico identificado nos artigos foi a Esquizoanálise dos autores Deleuze e Guat$\operatorname{tari}^{11,42}$. Alguns desses artigos não declaram possuir uma fundamentação esquizoanalítica, mas utilizam termos e noções próprias do campo, e por essa razão foram assim classificados. A esquizoanálise corresponde à uma das correntes do Movimento Institucionalista. Esta corrente possui fundamentação psicanalítica e, assim como as demais correntes do movimento, tem como objetivo promover análises do funcionamento das instituições. Como coloca Baremblitt ${ }^{43}$ As diferentes escolas do movimento institucionalista se propõem propiciar, apoiar, deflagrar nas comunidades, nos coletivos, nos conjuntos de pessoas, processos de autoanálise e autogestão (p. 14).

A Ergologia também aparece como uma referência importante para se discutir processos de trabalho e Cogestão ${ }^{44,45,20}$. A Ergologia, como definida em entrevista por seu fundador, Yves Schwartz, é o estudo da atividade humana, do trabalho concreto realizado no cotidiano. A noção básica é a de que o trabalho é sempre ressingularizado ou renormalizado pelo indivíduo que o executa, não havendo um padrão na execução; por mais que se crie normas, o trabalhador possui uma forma peculiar de atuar ${ }^{46}$.

Por fim, em menor frequência foram encontrados artigos em diálogo com: 1) a Hermenêutica, principalmente considerando o foco nas relações intersubjetivas ${ }^{47}$; 2) com a Pedagogia da Libertação de Paulo Freire ${ }^{48}$, em que se discute a construção do protagonismo a partir da revela- 
ção dos que estão em posição de dominação; 3) com noções de democracia conforme trabalhadas pelo sociólogo Habermas em sua Teoria do Agir Comunicativo $^{49}$.

\section{Relatos sobre a cogestão na prática}

Com relação aos arranjos práticos da Cogestão, grande parte dos artigos indica uma combinação de ações. Embora didaticamente algumas ações apareçam aqui de forma separada para que pudéssemos realizar um levantamento, há a combinação delas nos relatos sobre o estabelecimento da Cogestão. Destacamos a importância de se realizar uma análise das combinações possíveis e de seus resultados, porém optamos por nos ater ao recorte por nós estabelecido de explorar nesses relatos noções da prática separadamente.

Os artigos que descrevem relatos apresentam experiências de Cogestão através da prática do Apoio Institucional. Esta metodologia é descrita na obra de Campos ${ }^{1}$, tendo sido adotada pelo Ministério da Saúde que vinha oferecendo há alguns anos cursos de formação para apoiadores institucionais.

As experiências relatadas nesses artigos descrevem a implantação do Apoio através de estratégias, tais como: reuniões de diferentes modalidades entre profissionais - discussão de caso, planejamento e avaliação, reuniões com outros equipamentos de saúde, rodas etc. 19,38,20-22,23,26,33; reuniões com inclusão dos usuários ${ }^{31,26}$; reforma no fluxograma das unidades ${ }^{24}$; implantação de Grupo de Trabalho ${ }^{24,26}$; implantação de Conselho Gestor, Colegiados de Gestão e Contrato de Gestão ${ }^{17,18,20-22,26,29,33,38}$; Câmara Técnica e Colegiado Gestor $^{27}$; Fóruns de Humanização ${ }^{29}$; Grupo de Apoio à Gerência de políticas e programas ${ }^{33}$; visitas técnicas ${ }^{18}$; e Seminários, cursos de formação ou oficinas ${ }^{19,20,23,26,27,29}$.

Outros artigos, que não necessariamente enfocam o Apoio Institucional, também descrevem a composição de espaços coletivos de discussão, uma vez que essa é a base indicada na cartilha sobre a Cogestão, como por exemplo o Grupo de Trabalho de Humanização e Reunião Geral ${ }^{35,50}$; espaços de Educação Permanente em Saúde e Rodas de Conversa ${ }^{28,37,49}$; Reuniões de Equipe ${ }^{51}$; implantação de Colegiados de Gestão e Contratos de Gestão, Oficinas e Seminários sobre a Cogestão ${ }^{35,37}$; Seminário de discussão ${ }^{44}$; reformas administrativas e implantação de mesas de negociação permanente (sobre questões trabalhistas) ${ }^{37}$; Núcleo Técnico de Humanização ${ }^{35}$ ou com o fomento de maior participação dos trabalhadores das decisões ${ }^{48}$.
Uma outra estratégia relatada como cogestão na prática foi a chamada Comunidade Ampliada de Pesquisa ${ }^{32,39}$, que corresponde a um método de análise dos processos de trabalho. Essa estratégia pode dar início à Cogestão (promovendo análises do processo de trabalho), ou funcionar enquanto prática de Cogestão.

Já o material oficial identificado nessa revisão e produzido pelo $\mathrm{MS}^{2,52,53}$ apresenta a humanização no contexto da Atenção Básica reforçando o caráter participativo dos usuários ${ }^{52}$; apresenta diretrizes para monitoramento e avaliação das propostas, algo bastante técnico e detalhado, buscando direcionar ações possíveis de humanização em vários contextos e ambas as dimensões (assistência e gestão) com parâmetros prévios para avaliá-las ${ }^{53}$, e apresenta material específico sobre a Cogestão ${ }^{2}$, o qual indica dispositivos possíveis (listados na cartilha) para colocá-la em prática no que se refere à organização de espaços coletivos.

De forma geral, o que se torna comum às experiências corresponde à abertura de espaços com a participação de profissionais e gestores nos diversos contextos, e em menor escala com usuários. Esses espaços são descritos como momentos de discussão, reflexão e análise dos problemas e necessidades das unidades de saúde e levantamento de propostas de solução.

Alguns dos artigos descrevem a necessidade de adesão dos gestores para que as propostas ocorram de forma adequada ${ }^{20,22,23,27,32,39}$. Além disso, apresentam desafios como alta rotatividade dos profissionais ${ }^{13,24}$, baixa participação apesar de estarem presentes nas reuniões ${ }^{13,40}$; mudanças políticas e a falta de espaços físicos ${ }^{27}$; falta de preparo para lidar com situações conflituosas ${ }^{24}$ e de tempo para realizar as reuniões ${ }^{19}$; baixa participação dos usuários ${ }^{22}$; perda de autonomia no trabalho por precisar colocar os assuntos para serem discutidos antes de tomar decisões ${ }^{23}$.

Por outro lado, indicam mudanças importantes em alguns contextos em que os profissionais passaram a ter uma maior participação das decisões e do planejamento das unidades ${ }^{22,23,24,28,29,50,32}$, além de ativação de rede de coletivos, e mudanças no modelo de atenção e gestão, com apropriação das práticas de gestão pelos trabalhadores ${ }^{23}$.

\section{Discussão}

É possível notar que os dispositivos descritos na cartilha de Cogestão ${ }^{2}$ vêm sendo relatados como instrumentos norteadores da prática. Alguns em maior frequência como os Colegiados Gestores 
e Contratos de Gestão, mas de modo geral, foram identificados relatos de experiência que se referiam a todos esses dispositivos na literatura, o que pode ser considerado algo positivo, uma vez que sugere a "aplicação prática" da política. Por outro lado, a simples "aplicação" não garante o sucesso de um processo como a Cogestão, que leva em consideração, em seu delineamento original, o aspecto subjetivo e a comunicação de seus participantes. Da mesma forma, a estratégia de monitoramento e avaliação ${ }^{53}$ não contempla esses aspectos, parecendo-nos rígida e pautada em técnicas que antecedem os encontros.

Embora alguns artigos façam apontamentos importantes sobre a Cogestão não corresponder à junção de pessoas em espaços coletivos, havendo a necessidade de se possuir recursos para trabalhar com as subjetividades, relações e, até mesmo, com os conflitos ${ }^{12,20,21,22,24,26,47,49,51}$, de maneira geral, o que se percebe é que a cogestão, criada para transformar as subjetividades e processos de trabalho, acaba sendo ressignificada.

$\mathrm{Na}$ prática, a partir dos relatos publicados e selecionados, a Cogestão parece ter se transformado na promoção de reuniões que institucionalizam espaços para diálogo, como se a abertura do espaço fosse um resultado positivo em si mesmo, indicando, sem que seja necessária análise, processo grupal participativo. Assim, a forma como esses relatos são descritos sugere apropriação do método como nova técnica que, ao invés de promover reflexão, promove, em muitos casos, mera reprodução. Como apontam Mori et al..$^{39}$ Os dispositivos não são 'coisas' prontas que se implantam em determinados serviços sem que se coloquem em análise as formas de organização que os processos de trabalho têm produzido (p.724).

Além disso, boa parte dos artigos indica como sendo fundamental o apoio dos gestores. Certamente esse apoio é importante, mas de certa forma, a sua necessidade pode denunciar um paradoxo ou uma limitação do método em seu objetivo, pois na prática, a cogestão que pretende fomentar protagonismo, autonomia e relações democráticas deve, antes de mais nada, ter o consentimento dos, hierarquicamente, superiores. É como se o modelo indicado conseguisse atingir apenas uma transformação controlada que ainda mantém a lógica que almeja transformar. $\mathrm{Ou}$ as vicissitudes da prática, nas contradições do cotidiano, criam esses constrangimentos?

Embora consideremos os aspectos positivos destacados nos artigos, de que houve uma maior participação, melhoria na qualidade dos processos de trabalho, dentre outras, compreendemos faltar nesses artigos, para além dos relatos e afirmações, material empírico analisado, demonstrações concretas de transformação. Buscamos, com essa análise, fazer reflexões que convidem os estudiosos e profissionais a pensarem em outras possibilidades para além das já indicadas na cartilha. Desse modo, levantamos as seguintes questões: com base na história dos modelos participativos de gestão, que outras apostas metodológicas seriam profícuas? Como desenvolver gestão participativa considerando que a abertura de espaço não garante a participação?

Os artigos analisados apontam desafios para aplicação dos dispositivos indicados na cartilha, como resistência dos próprios trabalhadores, falta de tempo, falta de recursos humanos e físicos, falta de formação adequada, etc, mas a análise indica haver escassos apontamentos sobre o que se perde, ou, quais são os limites, ao adotar o modelo participativo indicado junto à diretriz Cogestão, ou ainda, quais são os limites impostos pelo contexto e pela cultura Capitalista vigente.

Com relação às perspectivas teóricas identificadas para se pensar a Cogestão, foi possível perceber que, com exceção da Ergologia de Schwartz, as demais perspectivas aparecem como referencial na obra de Campos's. Se, por um lado, é coerente que os estudos sejam desenvolvidos dentro da lógica teórica que orientou a cartilha que indica sua proposição prática, ao mesmo tempo, cria-se um limite em que a proposta passa a ser reificada como um valor, como algo bom em si mesmo, excluindo outros modelos existentes e anteriores.

Assim, a análise das produções científicas localizadas nesse recorte proporcionado pela revisão indica que, em termos práticos, o modelo tem sido adotado como mais uma consecução de passos, de estratégias e técnicas para a construção dos espaços coletivos, havendo pouca análise sobre o processo relacional desses espaços, ou análises que indiquem as limitações dos dispositivos práticos, com apresentação de novas propostas teóricas e práticas com a intenção, não de substituí-lo, mas de agregar novas possibilidades de ação.

\section{Considerações finais}

Apresentamos nesse artigo revisão integrativa da literatura que buscou mapear as discussões teóricas e relatos práticos publicados sobre o modelo de gestão participativa desde a sua inclusão na PNH em 2003.

Dentre os resultados apontados, destacamos que boa parte dos artigos dialoga com o autor 
criador do Método da Roda ${ }^{1}$, o qual pretende fomentar espaços relacionais de gestão. A Ergologia aparece em destaque por ser uma corrente teórica distinta das já contempladas na obra de Campos ${ }^{1}$. Com relação às experiências práticas foi possível observar que há a busca por implementação de espaços coletivos. Boa parte dos dispositivos indicados pela $\mathrm{PNH}$ aparecem nos artigos, e outros espaços coletivos são criados com nomes distintos, mas mesma função.

Porém, em nossa análise observamos que o método relacional, e que objetiva contemplar outros aspectos para além do planejamento administrativo, tem sido descrito de maneira técnica, com pouca atenção aos processos de comunicação e aos modos de construção relacional desses espaços. Apesar de haver algumas discussões nesse sentido, os artigos não aprofundam em teorias ou metodologias que norteiem práticas relacionais de construção da cogestão.

Os resultados apresentados correspondem à análise de revisão de literatura, a qual se fez através de um recorte das publicações encontradas na área. Vale destacar que esse recorte, não necessariamente, representa o modo como a cogestão tem sido trabalhada nos diversos contextos do Brasil. Além disso, a análise se baseou na construção de sentidos sobre as leituras realizadas pelas autoras, o que significa dizer que passou por um processo de significação do material encontrado e, não necessariamente, corresponde às intenções ou ideias originais dos autores dos textos, corresponde a uma leitura realizada com objetivo específico, conforme já detalhado.

Como uma limitação do estudo apresentado indicamos a não ampliação dos textos para além dos que foram encontrados nas plataformas de pesquisa. Sabemos que as referências bibliográficas de cada texto trazem outras sobre a temática estudada, porém essas não foram incluídas por se tratar de uma revisão sistemática integrativa. Além disso, nossa análise sobre as experiências práticas partem dos relatos de práticas e não das práticas em si, visto que não estivemos no cotidiano para analisar em profundidade o que se passava nos locais relatados nos estudos.

Por fim, buscamos ao longo do artigo levantar reflexões e questões que funcionam como ideias ou aberturas para novos estudos e pesquisas sobre a temática, que possam oferecer análises ou teorias inovadoras de gestão. Da mesma forma, pretendemos que as reflexões apontadas funcionem como chamada para que as experiências locais sejam relatadas e publicadas, o que facilitaria o acesso ao que se vem construindo no cotidiano, nas práticas locais.

\section{Colaboradores}

GC Doricci executou a pesquisa, análise e redação do material. C Guanaes-Lorenzi orientou todas as etapas e revisou o conteúdo deste artigo.

\section{Agradecimentos}

À Fundação de Amparo à Pesquisa do Estado de São Paulo (FAPESP). 


\section{Referências}

1. Campos GWS. Um método para análise e co-gestão de Coletivos. 3a ed. São Paulo: Hucitec; 2007.

2. Brasil. Política Nacional de Humanização da Atenção $e$ Gestão do SUS. Gestão Participativa e Cogestão. Série B. Textos Básicos de Saúde, Brasília: Ministério da Saúde; 2012.

3. Pereira AB, Ferreira Neto JL. Processo de implantação da Política Nacional de Humanização em Hospital Geral Público. Trab Educ Saude 2015; 13(1):67-88.

4. Coelho JS. Construindo a participação social no SUS: um constante repensar em busca de equidade e transformação. Saúde e Sociedade 2012; 21(Supl. 1):138151.

5. Carvalho AI. Conselhos de Saúde no Brasil: Participação Cidadã e Controle Social. Rio de Janeiro: IBAM/ FASE; 1995.

6. Serapioni M, Romani O. Potencialidades e desafios da participação em instâncias colegiadas dos sistemas de saúde: os casos de Itália, Inglaterra e Brasil. Cad Saude Publica 2006; 22(11):2411-2421.

7. Lopes MCR, Matta GC. SUS, gestão participativa e equidade. In: Guizardi FL, Nespoli G, Cunha LMS, Machado F, Lopes M organizadores. Políticas de Participação e Saúde. $1^{\text {a }}$ ed. Recife: Editora Universitária UFPE; 2014. p. 305-324.

8. Marinho PS. Gestão Participativa nas políticas públicas no âmbito do Sistema Único de Saúde: principais componentes e desafios. Cadernos Ibero-Americanos de Direito Sanitário 2015; 4(1):120-142.

9. Sandström C. Institutional Dimensions of Comanagement: Participation, Power and Process. Society \& Natural Resources 2009; 22:230-240.

10. Koopman PL, Wierdsma AFM. Participative Management. In. Drenth PJD, Thierry H, Wolff CJ editors. Handbook of Work and Organizational Psychology. East Sussex, UK: Psychology Press Ltda; 1998. p. 297317.

11. West E. Management matters: the link between hospital organisation and quality of patient care. Quality in Health Care 2001; 10:40-48.

12. Blaise P, Kegels G. A realistic approach to the evaluation of the quality management movement in health care systems: a comparison between European and African contexts based on Mintzberg's organizational models. Int J Health Plan and Management 2004; 19: 337-364.

13. Fontoura AMT. Arranjos e estratégias de cogestão em maternidades públicas [dissertação]. Rio de Janeiro: Fundação Oswaldo Cruz; 2017.

14. Botelho LLR, Cunha CCA, Macedo M. O método da revisão integrativa nos estudos organizacionais. Gestão Soc 2011; 5(11):121-136.

15. Mendes KDS, Silveira RCCP, Galvão CM. Revisão Integrativa: método de pesquisa para a incorporação de evidências na saúde e na Enfermagem. Texto \& Contexto Enfermagem 2008; 17(4):758-764.

16. Spink MJP, organizador. Práticas discursivas e produção de sentidos no cotidiano: aproximações teóricas e metodológica. 3a ed. São Paulo: Cortez; 2004.
17. Mori ME, Oliveira OVM. Os coletivos da Política Nacional de Humanização (PNH): a cogestão em ato. Interface (Botucatu) 2009; 13(Supl. 1):627-40.

18. Pereira AB, Ferreira Neto JL. Processo de implantação da Política Nacional de Humanização em Hospital Geral Público. Trab Educ Saude 2015; 13(Supl. 1):67-88.

19. Mori ME, Oliveira OVM. Apoio institucional e cogestão: a experiência da Política Nacional de Humanização no Sistema Único de Saúde (SUS) no Distrito Federal, Brasil. Interface (Botucatu) 2014; 18:1063-1075.

20. Shimizu HE, Martins T. O apoio institucional como método de análise-intervenção na Atenção Básica no Distrito Federal, Brasil. Interface (Botucatu) 2014; 18:1077-1087.

21. Martins CP, Luzio CA. Experimentações no apoio a partir das apostas da Política Nacional de Humanização - HumanizaSUS. Interface (Botucatu) 2014; 18:1099-1106.

22. Maerschner RL, Bastos ENE, Gomes AMA, Jorge MSB, Diniz SAN. Apoio institucional - reordenamento dos processos de trabalho: sementes lançadas para uma gestão indutora de reflexões. Interface (Botucatu) 2014; 18:1089-1098.

23. Pinheiro MEC, Jesus LMM. Apoio institucional como diretriz de gestão da 7a Diretoria Regional de Saúde, Bahia, Brasil. Interface (Botucatu) 2014; 18:1135-1143.

24. Calderon DBL, Verdi MIM. Cogestão e processo de intervenção de apoiadores da Política Nacional de Humanização (PNH). Interface (Botucatu) 2014; 18(Supl. 1):859-870.

25. Santos Filho SB. Apoio institucional e análise do trabalho em saúde: dimensões avaliativas e experiências no Sistema Único de Saúde (SUS). Interface (Botucatu) 2014; 18: 1013-1025.

26. Pavan, C, Trajano ARC. Apoio institucional e a experiência da Política Nacional de Humanização (PNH) na Freguesia do Ó, Brasilândia, São Paulo, Brasil. Interface (Botucatu) 2014; 18(Supl.1):1027-1040.

27. Roza MMR, Barros MEB, Guedes CR, Santos Filho SB. A experiência de um processo de formação articulando humanização e apoio institucional no trabalho em saúde. Interface (Botucatu) 2014; 18(Supl. 1):1041-1052.

28. Andrade MAC, Barros SMM, Maciel NP, Sodré F, Lima RCD. Apoio institucional: estratégia democrática na prática cotidiana do Sistema Único de Saúde (SUS). Interface (Botucatu) 2014; 18 (Supl. 1): 833844.

29. Guedes CR, Roza MMR, Barros MEB. O apoio institucional na Política Nacional de Humanização: uma experiência de transformação das práticas de produção de saúde na rede de atenção básica. Cad Saude Colet 2012; 20(1):93-101.

30. Santos Filho SB, Barros MEB, Gomes RS. A Política Nacional de Humanização como política que se faz no processo de trabalho em saúde. Interface (Botucatu) 2009; 13:603-613.

31. Guedes CR, Pitombo LB, Barros MEB. Os processos de formação na Política Nacional de Humanização: a experiência de um curso para gestores e trabalhadores da atenção em saúde. Physis 2009; 19(4):1087-1109. 
32. Barros MEB, Guedes CR, Roza MMR. O apoio institucional como método de análise-intervenção no âmbito das políticas públicas de saúde: a experiência em um hospital geral. Cien Saude Colet 2011; 16(12):4803-1814.

33. Cardoso JR, Oliveira GN, Furlan PG. Gestão democrática e práticas de apoio institucional na Atenção Primária à Saúde no Distrito Federal, Brasil. Cad Saude Publica 2016; 32(3): e00009315.

34. Pasche DF. Política Nacional de Humanização como aposta na produção coletiva de mudanças nos modos de gerir e cuidar. Interface (Botucatu) 2009; 13(Supl. 1):701-708.

35. Rios IC, Battistella LR. Gestão da humanização das práticas de saúde: o caso do Hospital das Clínicas da Faculdade de Medicina da Universidade de São Paulo. Saaude Soc 2013; 22(3):853-865.

36. Granja GF, Zoboli ELCP. Humanização da Atenção Primária à Saúde: Gestão em redes e governança local. O Mundo da Saúde 2012; 36(3):494-501.

37. Santos Filho SB, Figueiredo VON. Contratos internos de gestão no contexto da Política de Humanização: experimentando uma metodologia no referencial da cogestão. Interface (Botucatu) 2009; 13:615-626.

38. Deus AD, Melo EM. Avaliação de uma experiência de gestão hospitalar participativa no âmbito do SUS: produção de saúde, sujeitos de coletivos. Saude Debate 2015; 39(106):601-615.

39. Mori ME, Silva FH, Beck FL. Comunidade Ampliada de Pesquisa (CAP) como dispositivo de cogestão: uma aposta no plano coletivo. Interface (Botucatu) 2009; 13 (Supl. 1):719-727.

40. Trad LAB, Espiridião MA. Gestão Participativa e corresponsabilidade em saúde: limites e possibilidades no âmbito da ESF. Interface (Botucatu) 2009; 13 (Supl. 1):557-570.

41. Pasche DF, Passos E, Hennington EA. Cinco anos da Política Nacional de Humanização: trajetória de uma política pública. Cien Saude Colet 2011; 16(11):45414548.

42. Ceccim RB, Merhy EE. Um agir micropolítico e pedagógico intenso: a humanização entre laços e perspectivas. Interface (Botucatu) 2009; 13(Supl. 1):531-542.

43. Baremblitt G. Compêndio de Análise Institucional e outras correntes. Teoria e Prática 2a ed. Rio de Janeiro: Editora Rosa dos tempos; 1994.

44. Heckert ALC, Passos E, Barros MEB. Um seminário dispositivo: a humanização do Sistema de Saúde (SUS) em debate. Interface (Botucatu) 2009; 13(Supl. 1):493-502.

45. Hennington EA. Gestão dos processos de trabalho e humanização em saúde: reflexões a partir da ergologia. Rev Saude Publica 2008; 42(3):555-561.

46. Viegas MF. Histórico e conceitos da ergologia: entrevista com Yves Schwartz. Reflexão \& Ação 2012; 21(1):327-340

47. Santos JGW, Santo MAAE. Administração de Recursos Humanos em Saúde e Humanização: o viés hermenêutico. Revista Pan-Amazônica de Saúde 2011; 2(3):51-58.
48. Ferreira JA, Araújo GC. Humanização na saúde: uma análise dos sentidos na óptica do trabalho cotidiano. Textos \& Contextos 2014; 13(1):199-213.

49. Araújo CEL, Pontes RJS. Constituição de sujeitos na gestão em saúde: avanços e desafios da experiência de Fortaleza (CE). Cien Saude Colet 2012; 17(9):23572365.

50. Becchi AC, Albiero ALM, Pavão FO, Pinto IS, Godoi AV, Dias BC, Gonçalves ECA, Cavalhero RF. Perspectivas atuais de cogestão em saúde: vivências do Grupo de Trabalho de Humanização na Atenção Primária à Saúde. Saude Soc 2013; 22(2):653-660.

51. Cardoso CG, Hennington EA. Trabalho em Equipe e Reuniões Multiprofissionais de Saúde: uma construção à espera pelos sujeitos da mudança. Trab Educ Saude 2011; 9:85-112.

52. Brasil. Ministério da Saúde (MS). HumanizaSUS na Atenção Básica. Brasília: MS; 2006. (Série B. Textos Básicos de Saúde)

53. Brasil. Ministério da Saúde (MS). Monitoramento e Avaliação na Política Nacional de Humanização na Rede de Atenção e Gestão do SUS. Manual com eixos avaliativos e indicadores de referência. Brasília: MS; 2012. (Série B. Textos Básicos de Saúde)

Artigo apresentado em 14/01/2019

Aprovado em 16/09/2019

Versão final apresentada em 18/09/2019

Editores-chefes: Romeu Gomes, Antônio Augusto Moura da Silva 
